CLAWAR 2018: 21st International Conference on Climbing and Walking Robots and the Support Technologies for Mobile Machines, Panama City, Panama, 10-12 September 2018

\title{
DISTRIBUTED DRIVING SYSTEM FOR THE EXCAVATION UNIT OF A LUNAR EARTHWARM-TYPE "LEAVO" EXCAVATION ROBOT
}

\author{
AMI FUJIWARA, TOYOHARU NAKATAKE, NAOAKI TADAMI, KEITA ISAKA, \\ YASUYUKI YAMADA AND TARO NAKAMURA \\ Faculty of Science and Engineering, Chuo University, \\ 1-13-27 Kasuga, Tokyo 112-8551, Japan \\ HIROTAKA SAWADA AND TAKASHI KUBOTA \\ Japan Aerospace Exploration Agency (JAXA), 3-1-1 Chuo-ku, \\ Sagamihara-shi, Kanagawa 252-5210, Japan
}

\begin{abstract}
The authors have developed a small excavation robot called the "LEAVO" for lunar exploration, and they have confirmed its usefulness as an excavation robot. They then attempted to add a curved excavation function in order for the LEAVO to increase its exploration field. To achieve this goal, it was necessary for the LEAVO's excavation unit to transmit the motor output torque to the excavation head without any losses. In this paper, therefore, the authors proposed a new driving system called the "distributed driving system," which reduced the transmission losses by distributing the actuators and arranging them in the frontal part of the robot. Moreover, the authors developed the prototype of this system and measured its output torque as an operational check.
\end{abstract}

\section{Introduction}

In recent years, many lunar explorations have been initiated. However, there has not been enough exploration of the underground of the moon. An analysis of the components and internal construction of the underground is needed to understand the origin of the planets. Therefore, the Japan Exploration Agency (JAXA) is considering lunar exploration missions that collect environmental data from buried sensors and analyze some underground regolith samples. ${ }^{1}$ For these planetary underground exploration missions, considering the transportation costs and safety issues, small excavation robots will be required.

Some small excavation robots have already been developed. For example, a mole-type robot was developed by Watanabe et al. ${ }^{2}$, and a screw-type buried robot was developed by Nagaoka et al. ${ }^{3}$ However, those robots are unsuitable for practical use because they are susceptible to earth pressure and have difficulty discharging soil. 
Therefore, in this research, the authors focused on the peristaltic crawling motion of an earthworm, which is not susceptible to earth pressure, and they developed a small excavation robot called the "LEAVO." "The LEAVO achieved a vertical excavation depth of $938 \mathrm{~mm}$. In that test, there was no decrease in the robot's excavation speed, and it was confirmed that the LEAVO was not susceptible to earth pressure. Therefore, the LEAVO proved its usefulness as a small excavation robot. ${ }^{5}$ However, the LEAVO could only excavate a straight direction at that time, and there was a limit to its exploration range. To increase the exploration range and improve the LEAVO's usefulness, it was necessary to add a curved excavation function. To achieve this function, it was necessary to transmit the motor power to the excavation heads efficiently. Therefore, in this paper, the authors propose a new driving system called the "distributed driving system" with distributed actuators, which can be set in the frontal part of the LEAVO. Moreover, the authors developed the distributed driving system and measured its maximum output torque as an operational check.

\section{Concept of the "LEAVO" Planetary Excavation Robot}

Figure 1 provides an overview of the LEAVO. As the figure shows, the LEAVO contains three basic units: propulsion, excavating, and discharging. The propulsion unit consists of a further three propulsion subunits. A propulsion subunit produces a peristaltic crawling motion by making itself expand and extend, which propels it in the hole and supports the reaction force during excavation. The excavation unit consists of an "earth auger," which is an excavation instrument, and a "casing pipe," which covers the earth auger. The earth auger not only excavates the soil in front of the LEAVO but also transports it to the back of the LEAVO. This is accomplished by screws at the back of the excavation head. The discharging unit clears the soil out of the borehole.

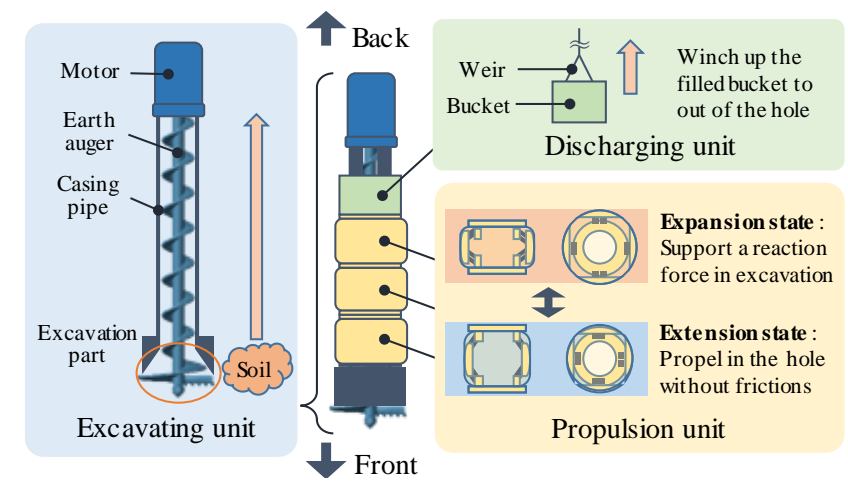

Figure 1. Overview of the LEAVO. 


\section{Curving excavation for spread of exploration ranges}

The usefulness of the LEAVO as a practicable excavation robot was confirmed in the excavation test. However, the LEAVO could excavate only in a linear direction and was limited in its exploration range. Therefore, the authors proposed to add a curved excavation function to the LEAVO. In this section, the authors describe the concept of curved excavation and bendable excavation instruments called the "flexible auger" and "both-ends-supported flexible auger", which the author developed to achieve curved excavation.

\subsection{Overview of curved excavation}

Figure 2 shows the concept of curved excavation. As the figure indicates, for this excavation method, authors decided to use the LEAVO Mk.5, which had bendable joint units between its propulsion subunits. In this excavation method: 1) the LEAVO excavates vertically to a certain depth; 2) the front bendable joint unit bends to change the excavation direction; 3) the excavation continues, and the propulsion maintains this posture. Using this excavation method, the LEAVO Mk.5 could excavate in a curved path.

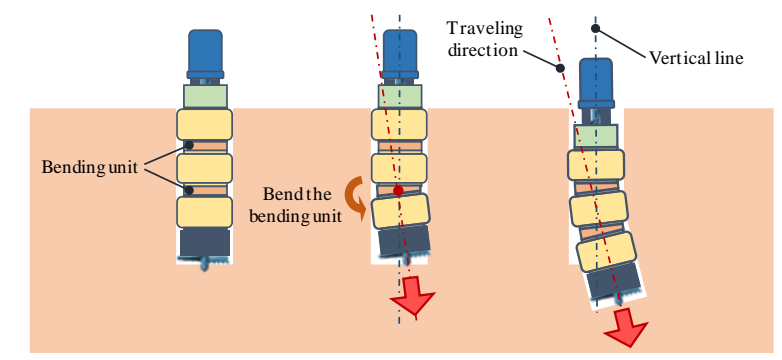

Figure 2. Overview of curved excavation.

\subsection{Flexible auger and both-ends-supported earth auger}

Figure 3 shows an overview of the flexible auger. This excavation instrument can bend passively because it has two universal joints between its earth auger parts. The flexible auger excavated a curved borehole in the excavation test owing to its curved casing pipe. However, it was supported only at its back end, and the axis of rotation of the excavation head was unstable.

Figure 4 shows an overview of the both-ends-supported flexible auger, which was developed to address the problems of the flexible auger. As this figure indicates, the both-ends-supported flexible auger has its rotation supported by a disk on its frontal part, which makes its axis of rotation stable. 
However, both the flexible auger and both-ends-supported flexible auger had some parts that inhibited the power transmissions between the motor and excavation head (e.g., universal joints and disk). Therefore, the authors proposed the "distributed driving system," which can be set on frontal part of the LEAVO, made its prototype, and measured its maximum output torque.

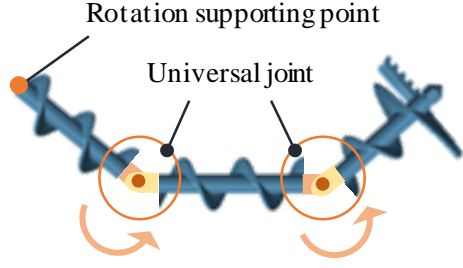

Figure 3. Flexible auger.

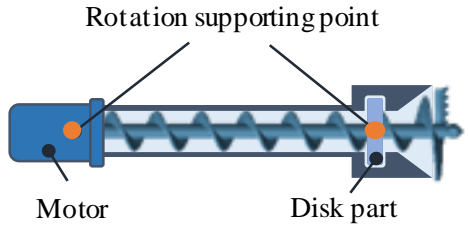

Figure 4. Both-ends-supported flexible auger.

\section{Distributed Driving System}

In this section, the authors describe the distributed driving system.

\subsection{Concept of the Distributed driving system}

Figure 5 shows the concept of the distributed driving system. As this figure indicates, in this system, a hollow gear was installed on the disk of the bothends-supported flexible auger. It is driven by small pinions, which are arranged around the disk. This system allows the motors to be set on or near the excavation head and can efficiently convert the motors' power to excavation torque. Moreover, with this system, the flexible auger is driven by several motors, which decreases the load on an individual motor. This is expected to easily allow the driving system to be made smaller.

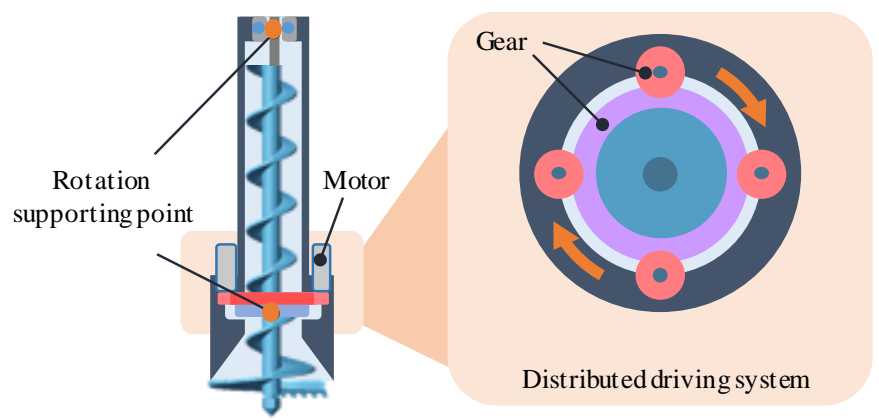

Figure 5. Concept of the distributed driving system. 


\subsection{Design of the distributed driving system}

Figure 6 shows an overview of the prototype of the distributed driving system, and Table 1 shows its theoretical specifications. In this system, four geared motors (reduction ratio $=172: 1$, Pololu Co.) are used. The reduction ratio of the overall system was determined by considering the excavation torque and speed of the LEAVO. The rotational speed was about $5 \mathrm{rpm}$ at an idling state, and the stall torque was about $27.5 \mathrm{Nm}$.

Moreover, a hollow-shaft gear was added to the construction of the disk to bear the burden of the excavation. Therefore, the disk was supported in its rotation by a radial bearing to accurately maintain the distance between the gear axes.

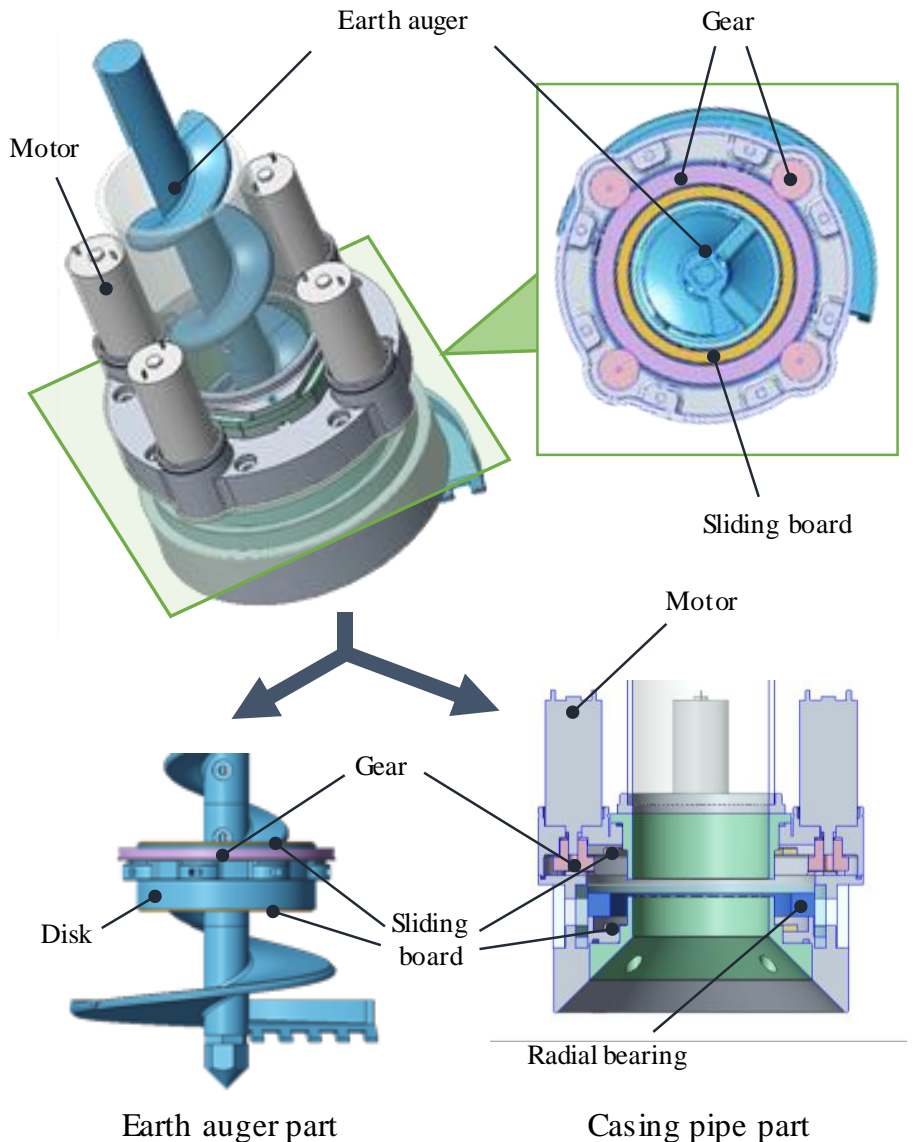

Figure 6. Prototype of the distributed driving system. 
6

Table 1. Specifications of the prototype of the distributed driving system

\begin{tabular}{ccc}
\hline Subject & Value & Condition \\
\hline Output torque $[\mathrm{N} \mathrm{m}]$ & 27.5 & Stall torque \\
Revolution per minutes $[\mathrm{r} / \mathrm{m}]$ & 5 & Free run \\
\hline
\end{tabular}

\subsection{Design of Dustproofing for the Distributed Driving System}

In the distributed driving system, soil easily invaded the system. This led to the flexible auger becoming inoperable because of clogged gears. Therefore, dustproofing was necessary. Figure 7 shows the design of the dustproofing system. As this figure indicates, two O-rings are arranged on the circumference of a disk. Because of this arrangement, the O-rings are not excessively deformed by the pushing force of the excavation. Moreover, although the O-rings have a high coefficient of friction, this arrangement can keep any increase of the driving torque to a minimum.

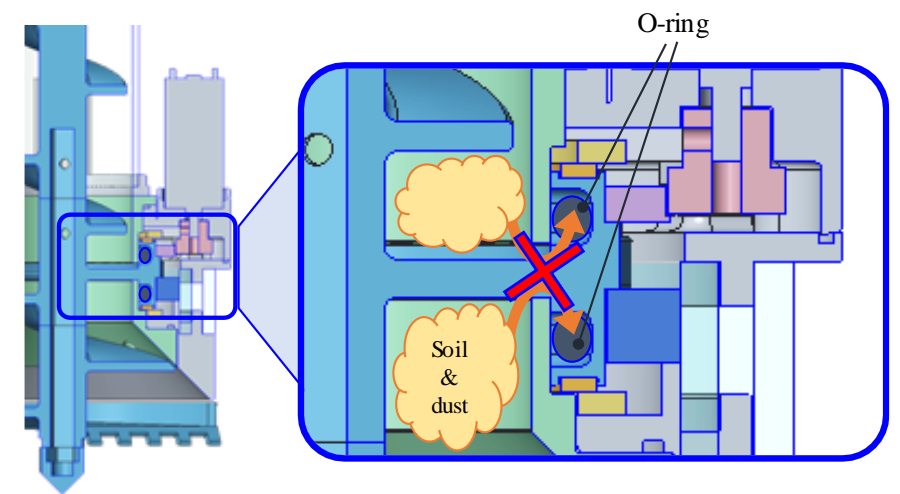

Figure 7. Overview of dustproofing system.

\section{Maximum Output Torque Check of the Distributed Driving-Type Excavation Unit}

In this section, as the distributed driving system's operational check, the maximum output torque was measured.

\subsection{Power check method}

Figure 8 shows the prototype of the distributed driving system, and Fig. 9 shows the environment of the operational check. As Fig. 9 indicates, in this check, a pulley (diameter $=\phi 160 \mathrm{~mm}$ ) was attached to the output shaft. Also, a wire was 
connected to the pulley. This wire's maximum string force in the driving state was measured by a force gauge, and the maximum output torque calculated from this value. Also, the maximum output torque was taken from the average of five measurements.
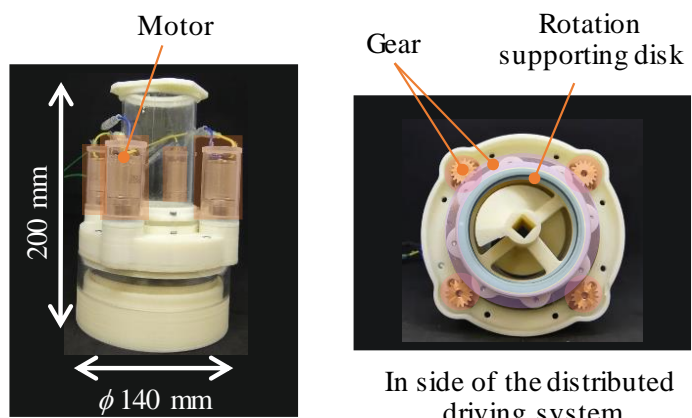

Figure 8. Appearance of the distributed driving system prototype.

\subsection{Result of the power check}

Table 2 shows the maximum output torque and the LEAVO's maximum excavation torque (this value is referenced from a previous study). From this result, the maximum output torque was sufficiently larger than the LEAVO's maximum excavation torque, and the excavation capacity of the distributed driving system was confirmed. The reason the maximum output torque was smaller than its designed value was assumed to be the friction force occurred in the dustproofing part.

Table 2. Results of the experiment

\begin{tabular}{cc}
\hline Distributed driving system's output torque $[\mathrm{N} \mathrm{m}]$ & 18.1 \\
\hline Excavation torque $[\mathrm{N} \mathrm{m}]$ & 13 \\
\hline
\end{tabular}

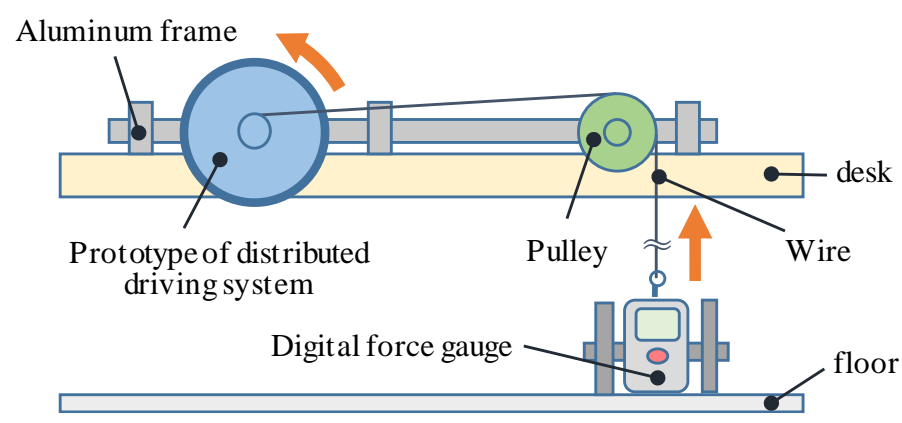

Figure 9. Overview of the power check experiment. 


\section{Conclusion}

In this paper, a distributed driving system was proposed to efficiently transmit the motor power. Moreover, a prototype of the distributed driving system was developed, and its excavation capacity was confirmed by an operational check.

In future works, the authors will look at the excavation efficiency by performing a test on the excavation unit with the distributed driving system.

\section{References}

1. K. Nagaoka, T. Kubota and M. Otsuki, Experimental study on autonomous burrowing screw robot for subsurface exploration on the Moon, in Proc. IEEE Int. Conf. on Intelligent Robots and Systems (IROS'08), (Nice, France 2008).

2. K. Watanabe, S. Shimoda, T. Kubota and I. Nakatani, A mole-type drilling robot for lunar sub-surface exploration, in Proc. Int. Symp. on Artificial Intelligence, Robotics and Automation in Space (i-SAIRAS'03), (Nara, Japan, 2003).

3. K. Nagaoka, T. Kubota, M. Otsuki and S. Tanaka, Robotic screw explorer for lunar subsurface investigation: Dynamics modeling and experimental validation, Proc. IEEE Int. Conf. on robotics and Automation (ICRA'09),(Kobe, Japan, 2009)

4. H. Omori, T. Murakami, H. Nagai, T. Nakamura and T. Kubota, Planetary Subsurface Explorer Robot with Propulsion Units for Peristaltic Crawling, Proc. IEEE Int. Conf. Robotics and Automation (ICRA'11), (Shanghai, China, 2011).

5. T. Nakatake, M. Konno, A. Mizushina, Y. Yamada, T. Nakamura and T. Kubota, Soil Circulating System for a Lunar Subsurface Explorer Robot Using a Peristaltic Crawling Mechanism, Proc. IEEE Int. Conf. on Advanced Intelligent Mechatronics (AIM'16), (Banff, Canada, 2016).

6. M. Nagai, C. Hirabayashi, Y. Yamada, T Nakamura and H. Yoshida, Development of a Flexible Excavation Unit for a Peristaltic Crawling Seabed Excavation Robot, Int. Conf. on Climbing and Walking Robots and Support Technologies for Mobile Machines (CLAWAR'16), ( London, UK, 2016).

7. A. Fujiwara, T. Nakatake, M. Nagai, N. Tadami, Y. Yamada, T. Nakamura, H. Sawada and T. Kubota, Both-ends supported earth auger for a bending excavation of peristaltic-type lunar excavation robot, Int. Conf. on Climbing and Walking Robots and Support Technologies for Mobile Machines (CLAWAR'17), (Porto, PT., 2017). 